\title{
Sutureless Surgical Orthotopic Implantation Technique of Primary and Metastatic Cancer in the Liver of Mouse Models
}

\author{
HIROTO NISHINO ${ }^{1,2,3}$, HANNAH M. HOLLANDSWORTH ${ }^{1,4}$, NORIHIKO SUGISAWA $^{1,2}$, JUN YAMAMOTO ${ }^{1,2}$, \\ YOSHIHIKO TASHIRO ${ }^{1,2}$, SACHIKO INUBUSHI $^{1,2}$, KAZUYUKI HAMADA $^{1,2}$, YU SUN $^{1,2}$, HYEIN LIM $^{1,2}$, \\ SIAMAK AMIRFAKHRI ${ }^{1,4}$, FILEMONI FILEMONI $^{1,4}$, ROBERT M. HOFFMAN $^{1,2,4}$ and MICHAEL BOUVET ${ }^{1,4}$ \\ ${ }^{1}$ Department of Surgery, University of California San Diego, San Diego, CA, U.S.A.; \\ ${ }^{2}$ AntiCancer, Inc., San Diego, CA, U.S.A.; \\ ${ }^{3}$ Department of Surgery, Graduate School of Medicine, Kyoto University, Kyoto, Japan; \\ ${ }^{4}$ Department of Surgery, VA San Diego Healthcare System, San Diego, CA, U.S.A.
}

\begin{abstract}
Background/Aim: Surgical orthotopic implantation (SOI) is used to establish patient-derived orthotopic xenograft (PDOX) and other orthotopic mouse models. Orthotopic liver models can be challenging, as the liver parenchyma is prone to bleeding. The present report describes a sutureless method to implant tumors in the liver that reduces bleeding and procedural time. Materials and Methods: Human HCC cell-line (Huh-7-GFP) and CM2, a patient-derived coloncancer liver metastasis, were used for sutureless SOI of tumor fragments in the liver of nude mice. A small cavity was formed on the liver surface. A solitary tumor fragment was implanted in the cavity without suturing to create hemostasis. Results: Six weeks after sutureless SOI, the tumor volume of Huh-7-GFP (n=5) was 584.41 \pm 147.64 $\mathrm{mm}^{3}$ and the tumor volume of CM2 (n=5) was $1336.54 \pm 1038.20 \mathrm{~mm}^{3}$. The engraftment rate was $100 \%$. Conclusion: This novel method for establishing orthotopic liver-implantation mouse models is suitable for studies of liver cancer and liver metastases due to its simple procedure and potential high engraftment rate.
\end{abstract}

Colorectal cancer is the third most common malignant disease worldwide (1). Approximately $15 \%$ of patients with colorectal cancer have synchronous liver metastases and approximately $30 \%$ have metachronous liver metastasis (2).

This article is freely accessible online.

Correspondence to: Michael Bouvet, MD, UCSD Moores Cancer Center, 3855 Health Sciences Drive \#0987, La Jolla, CA, 920930987, U.S.A. Tel: +1 8588226191, Fax: +1 8588226192, e-mail: mbouvet@ucsd.edu

Key Words: Hepatocellular carcinoma, colon cancer, liver metastasis, nude mouse, orthotopic, cell line, patient tumor, PDOX.
Primary liver cancer is the seventh-most-common cancer in the world and the second-most-frequent cause of cancer mortality (3). Hepatocellular carcinoma (HCC) is the mostfrequent form of primary liver cancer and often occurs in patients with chronic liver disease and cirrhosis (4).

Animal models serve as an important tool in the study of liver cancer and liver metastasis. A large number of mouse models have been designed to study the pathogenesis of tumors in the liver and investigate improved therapy $(5,6)$. The orthotopic xenograft model is the most clinically-relevant model of HCC (7-10) and liver metastasis (11-18). However, the mouse liver is fragile and difficult to handle, and prone to extensive bleeding, especially with the use of sutures.

Our laboratory has previously developed the technique of surgical orthotopic implantation (SOI), which was used to establish patient-derived orthotopic xenograft (PDOX) mouse models of all cancer types $(19,20)$. One of the more difficult PDOX and other orthotopic models involves liver implantation, since the liver parenchyma is fragile and prone to bleeding. The present report describes a sutureless method to implant tumors in the liver of nude mice to reduce bleeding and procedural time. Our aim was to develop a simpler mouse model of primary and metastatic liver cancer using sutureless SOI to the liver.

\section{Materials and Methods}

Animals. Male and female athymic nu/nu nude mice (AntiCancer, Inc., San Diego, CA, USA), 4-6 weeks old, were used in the present study. The animals were housed and fed as described in previous publications (21-23). Mice were routinely observed and sacrificed by $\mathrm{CO}_{2}$ inhalation with humane-endpoint criteria as previously described (21-23). All mice were processed according to the principles and procedures laid out in the National Institutes of Health Guide for the Care and Use of Animals under Assurance Number A3873-1 (21-23).

Cell line and cell culture. The well-differentiated human hepatocellularcarcinoma cell line Huh-7 expressing green fluorescent protein (GFP) (Huh-7-GFP) (AntiCancer, Inc.) (24) was maintained in DMEM (Irvine 


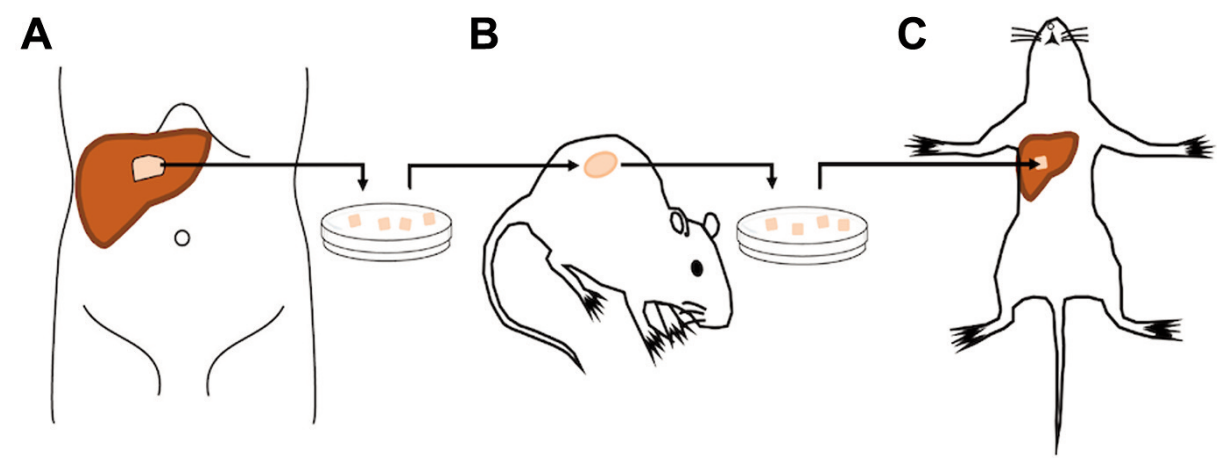

Figure 1. Establishment of an orthotopic mouse model of tumor implantation in the liver without suturing. A) Liver metastasectomy from a human colon-cancer liver-metastasis patient. B) Establishment of the liver metastasis in the mouse by subcutaneous transplantation. C) Sutureless surgical orthotopic implantation of a fragment of the harvested subcutaneous tumor in the liver.

Scientific, Irvine, CA, USA) supplemented with heat-inactivated $10 \%$ fetal bovine serum (FBS; Gemini Biologic Products, Calabasas, CA, USA), $2 \mathrm{mM}$ glutamine, $100 \mathrm{U} / \mathrm{ml}$ penicillin, $100 \mathrm{mg} / \mathrm{ml}$ streptomycin, and $0.25 \mathrm{mg} / \mathrm{ml}$ amphotericin B (Life Technologies, Inc. Grand Island, $\mathrm{NY}, \mathrm{USA}$ ). The cells were incubated at $37^{\circ} \mathrm{C}$ in $5 \% \mathrm{CO}_{2}$.

Cell-line tumor. Huh-7-GFP cells $\left(2 \times 10^{6}\right)$ in $0.1 \mathrm{ml}$ phosphatebuffered saline (PBS) were initially subcutaneously injected in the shoulder of nude mice. Resulting tumors were harvested and sectioned into small pieces for sutureless SOI to the liver.

Patient-derived tumor. A colon-cancer liver metastasis from a human patient was previously surgically obtained under standard sterile conditions at the UCSD Thornton hospital under UCSD IRB protocol 140046. Informed patient consent to utilize the tumor tissue for research was obtained prior to surgical resection (Figure 1A). Fresh tumor fragments were subcutaneously implanted in nude mice (Figure 1B). Once tumor growth was established subcutaneously, tumors were harvested and sectioned into small pieces for sutureless SOI to the liver (Figure 1C).

Sutureless SOI to the liver. Nude mice $(\mathrm{n}=10)$ were injected intramuscularly with a ketamine solution $(0.02 \mathrm{~mL})$ for anesthesia prior to all procedures. The entire abdomen was sterilized with a $70 \%$ ethanol solution. A $10-\mathrm{mm}$ incision was performed vertically in the midline of the upper abdomen through the skin and peritoneum (Figure 2A). After removal of the xiphoid process (Figure 2B), exposure of the left lobe of the liver was carefully performed (Figure 2C). A cavity was made with a 1-mm incision on the liver surface and spread gently with forceps to minimize bleeding (Figure 2D). Then, a single $1-\mathrm{mm}^{3}$ tumor fragment of either CM2 or Huh-7-GFP was embedded in the cavity as sutureless SOI (Figure 2E). The minimal bleeding created with the incision acts as a binder to ensure the tumor fragment remains within the incised cavity. After compression hemostasis was achieved, the liver was gently placed back in its anatomic position within the peritoneal cavity, with care to ensure the tumor remained within the surgical cavity. The abdominal wall and skin were closed with interrupted 6-0 surgical sutures (Ethicon Inc., Sommerville, NJ, USA) (Figure 2F). Post-operative pain was treated with subcutaneous buprenorphine.
Tumor size measurement and imaging. The size of the tumors was measured with calipers at the time of imaging after laparotomy. Tumor volume was estimated by measuring the perpendicular small (W) and large (L) dimensions. Approximate tumor volume $\left(\mathrm{mm}^{3}\right)$ was calculated using the formula $(\mathrm{W} \times \mathrm{W} \times \mathrm{L}) \times 1 / 2$. Mice were sacrificed 6 weeks after SOI. Bright light imaging was obtained at the time of laparotomy.

Statistical analysis. Statistical analysis was performed using SAS software (JMP 14.2.0; SAS Institute Inc., Cary, NC, USA). Continuous variables are presented as mean \pm standard deviation.

\section{Results}

Tumor development in the liver was observed in all mice and the engraftment rate was $100 \%$ after sutureless SOI. The Huh7-GFP tumor growing in the liver is shown in Figure 3A. The CM2 tumor growing in the liver is shown in Figure 3B. The final tumor volume of Huh-7-GFP was $584.41 \pm 147.64 \mathrm{~mm}^{3}$. The final tumor volume of CM2 was $1336.54 \pm 1038.20 \mathrm{~mm}^{3}$. The tumor volume growth curves are shown in Figure 3C. All mice survived until the 6-week point.

\section{Discussion}

In the present study, we demonstrated a novel method for the establishment of primary and metastatic tumors in the liver in mouse models, using sutureless SOI.

Various mouse models of orthotopic liver-tumor implantation have been previously reported (7-26). The method of the present study involves making a cavity with a small incision in the liver parenchyma, and packing of the tumor fragment in the incisional cavity which provides compression hemostasis and immobilizes the tumor without sutures, which could cause increased bleeding. The novel procedure also can be more rapid than the suturing SOI method. 
A

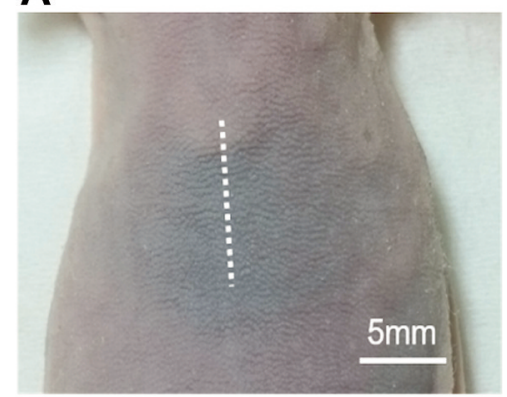

D

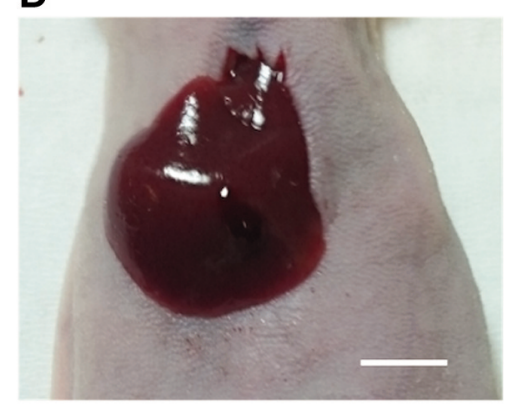

B

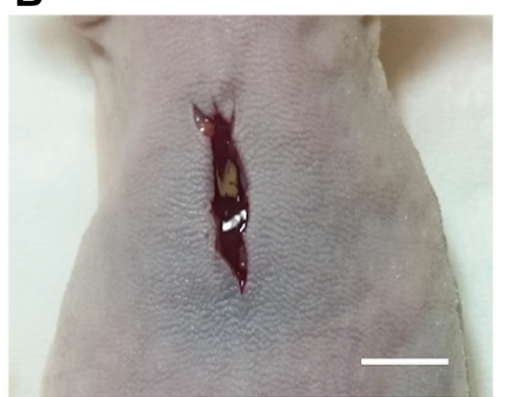

E

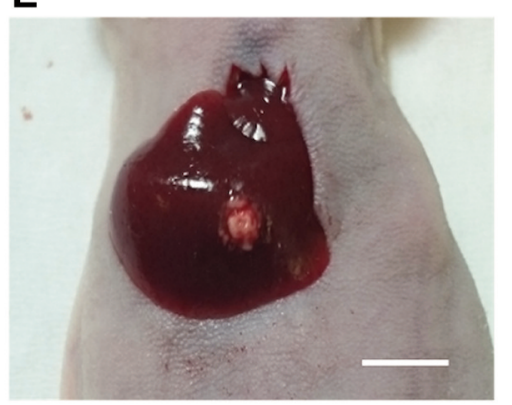

C

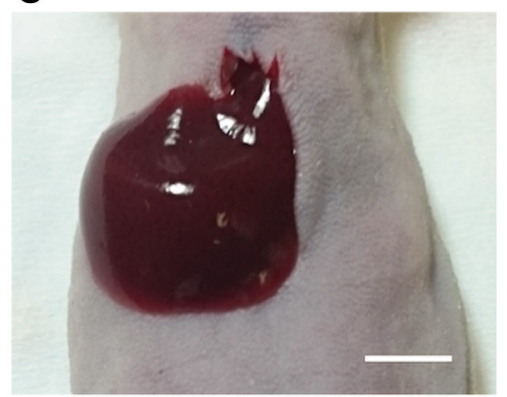

$\mathbf{F}$

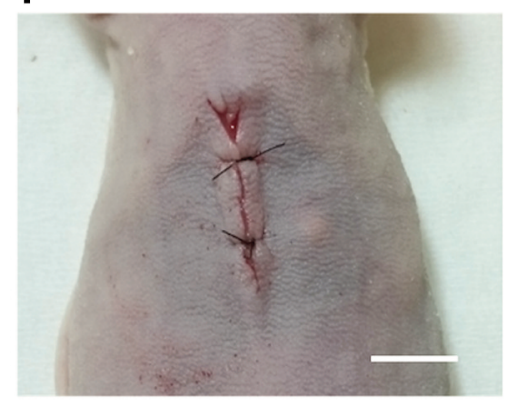

Figure 2. Procedure of sutureless surgical orthotopic implantation (SOI) of a fragment from a harvested subcutaneous tumor, in the liver parenchyma of a nude mouse (Scale bar: $5 \mathrm{~mm}$ ). A) A 10-mm incision was performed vertically in the midline of the upper abdomen. B) The xiphoid process was removed. C) Exposure of the left lobe of the liver was performed. D) A cavity was made by a 1-mm incision on the liver surface. E) A single 1$\mathrm{mm}^{3}$ tumor fragment was embedded in the cavity for SOI in the liver parenchyma without suturing. F) After hemostasis was achieved, the liver was placed back into the peritoneal cavity, and the abdominal wall and skin were closed.

A

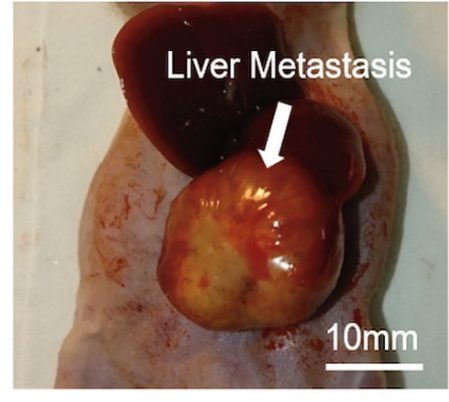

B

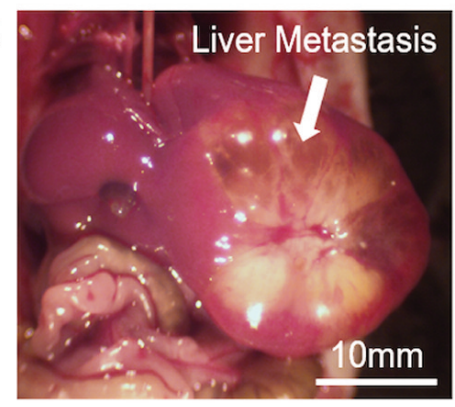

C Tumor
volume
$\left(\mathrm{mm}^{3}\right)$

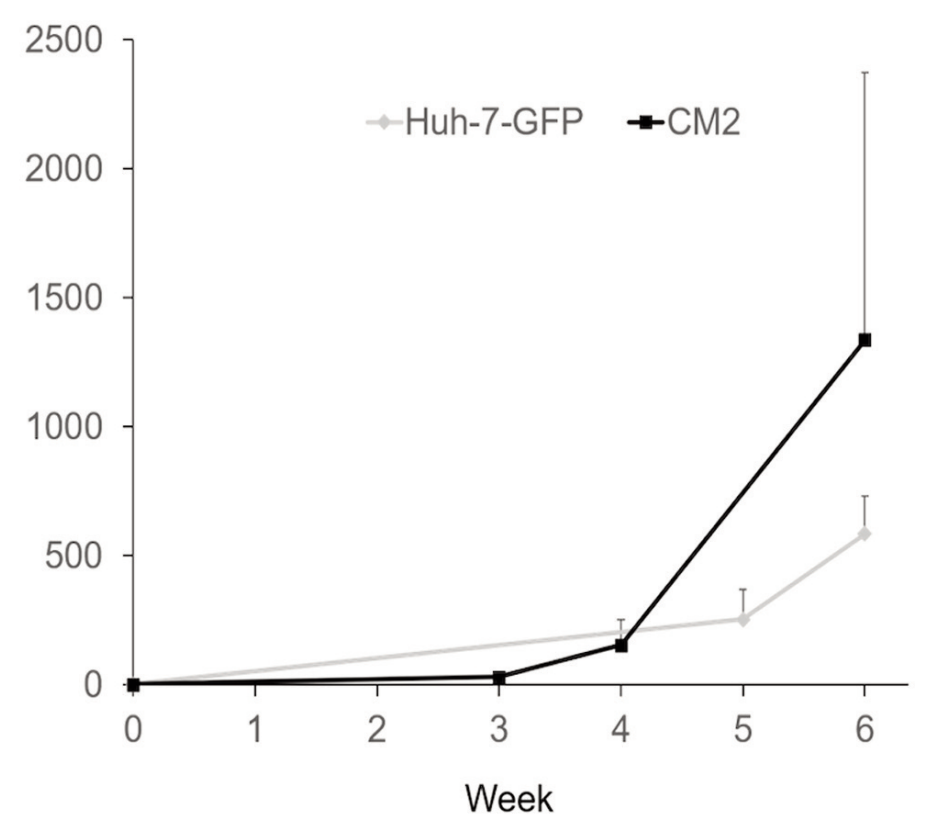

Figure 3. Growth of orthotopic tumors in the liver implanted with sutureless surgical orthotopic implantation (SOI). A) Tumor image 6 weeks after sutureless SOI of Huh-7-GFP (Scale bar: $10 \mathrm{~mm}$ ). B) Tumor image 6 weeks after sutureless SOI of CM2 to the liver (Scale bar: $10 \mathrm{~mm}$ ). C) The tumor volume change over time measured with calipers of Huh-7-GFP and CM2 growing in the liver of nude mice. 
Future studies will determine if sutureless SOI to the liver will reduce the possibility of adhesions to the abdominal wall due to post-operative bleeding or a suture. Future studies will also compare growth of the tumors in the liver implanted using sutures, to the sutureless method.

\section{Conflicts of Interest}

There is no financial or other interest in the submitted manuscript that could be construed as a conflict of interest.

\section{Authors' Contributions}

H.N., R.M.H. and M.B. designed the experiments. H.N., Y.T., J.Y., N.S., S.I., K.H., Y.S. and H.I.L. were involved in the acquisition of the data. H.M.H., S.A., and F.F. provided technical support and conceptual advice. H.N. and H.M.H. were involved in writing the manuscript. R.M.H. revised the manuscript. All Authors were involved in final manuscript editing and approval.

\section{Acknowledgements}

This study was funded by VA Merit Review grant numbers 1 I01 BX003856-01A1 and 1 I01 BX004494-01 (MB) and NIH/NCI T32CA121938 (HH).

\section{References}

1 Brenner H, Kloor M and Pox CP: Colorectal cancer. Lancet 383(9927): 1490-1502, 2014. PMID: 24225001. DOI: 10.1016/S0140-6736(13)61649-9

2 Manfredi S, Lepage C, Hatem C, Coatmeur O, Faivre J and Bouvier AM: Epidemiology and management of liver metastases from colorectal cancer. Ann Surg 244(2): 254-259, 2006. PMID: 16858188. DOI: $10.1097 / 01$.sla.0000217629.94941.cf

3 Bray F, Ferlay J, Soerjomataram I, Siegel RL, Torre LA and Jemal A: Global cancer statistics 2018: GLOBOCAN estimates of incidence and mortality worldwide for 36 cancers in 185 countries. CA Cancer J Clin 68(6): 394-424, 2018. PMID: 30207593. DOI: $10.3322 /$ caac. 21492

4 Ferlay J, Soerjomataram I, Dikshit R, Eser S, Mathers C, Rebelo M, Parkin DM, Forman D and Bray F: Cancer incidence and mortality worldwide: sources, methods and major patterns in GLOBOCAN 2012. Int J Cancer 136(5): E359-86, 2015. PMID: 25220842. DOI: $10.1002 /$ ijc. 29210

5 He L, Tian DA, Li PY and He XX: Mouse models of liver cancer: Progress and recommendations. Oncotarget 6(27): 23306-23322, 2015. PMID: 26259234. DOI: 10.18632/oncotarget.4202

6 Santos NP, Colaço AA and Oliveira PA: Animal models as a tool in hepatocellular carcinoma research: A Review. Tumour Biol 39(3): 1010428317695923, 2017. PMID: 28347231. DOI: $10.1177 / 1010428317695923$

7 Wang $M$, Zhang $X$, Xiong X, Yang Z, Sun Y, Yang Z, Hoffman RM and Liu Y: Efficacy of the Chinese traditional medicinal herb Celastrus orbiculatus Thunb on human hepatocellular carcinoma in an orthothopic fluorescent nude mouse model. Anticancer Res 32(4): 1213-1220, 2012. PMID: 22493351 .
8 Suetsugu A, Hiroshima Y, Matsumoto T, Hasagawa K, Nakamura M, Shimizu M, Saji S, Moriwaki H, Bouvet M and Hoffman RM: Recruitment of cancer-associated fibroblasts and blood vessels by orthotopic liver tumors imaged in red fluorescent protein (RFP) transgenic nude mice. Anticancer Res 35(11): 5821-5825, 2015. PMID: 26504003.

9 Zang W, Bian H, Huang X, Yin G, Zhang C, Han LI, Hao P, Ding S, Sun YU, Yang Z, Hoffman RM and Tang D: Traditional chinese medicine (TCM) Astragalus Membranaceus and Curcuma Wenyujin promote vascular normalization in tumorderived endothelial cells of human hepatocellular carcinoma. Anticancer Res 39(6): 2739-2747, 2019. PMID: 31177109. DOI: 10.21873/anticanres. 13400

10 Sun FX, Tang ZY, Lui KD, Ye SL, Xue Q, Gao DM and Ma ZC: Establishment of a metastatic model of human hepatocellular carcinoma in nude mice via orthotopic implantation of histologically intact tissues. Int J Cancer 66(2): 239-243, 1996. PMID: 8603818. DOI: 10.1002/(SICI)1097-0215(19960410) 66:2<239::AID-IJC17>3.0.CO;2-7

11 Rashidi B, Gamagami R, Sasson A, Sun FX, Geller J, Moossa AR and Hoffman RM: An orthotopic mouse model of remetastasis of human colon cancer liver metastasis. Clin Cancer Res 6(6): 2556-2561, 2000. PMID: 10873112.

12 Rashidi B, An Z, Sun FX, Moossa AR and Hoffman RM: Antimetastatic intraoperative chemotherapy of human colon tumors in the livers of nude mice. Clin Cancer Res 6(6): 24642468, 2000. PMID: 10873100.

13 Murakami T, Hiroshima Y, Zhang Y, Bouvet M, Chishima T, Tanaka K, Endo I and Hoffman RM: Improved disease-free survival and overall survival after fluorescence-guided surgery of liver metastasis in an orthotopic nude mouse model. J Surg Oncol 112(2): 119-124, 2015. PMID: 26266663. DOI: $10.1002 /$ jso. 23986

14 Murakami T, Hiroshima Y, Zhang Y, Chishima T, Tanaka K, Bouvet M, Endo I and Hoffman RM: Fluorescence-guided surgery of liver metastasis in orthotopic nude-mouse models. PLoS One 10(10): e0138752, 2015. PMID: 26427050. DOI: 10.1371/journal.pone.0138752

15 Hiroshima Y, Lwin TM, Murakami T, Mawy AA, Kuniya T, Chishima T, Endo I, Clary BM, Hoffman RM and Bouvet M: Effective fluorescence-guided surgery of liver metastasis using a fluorescent anti-CEA antibody. J Surg Oncol 114(8): 951-958, 2016. PMID: 27696448. DOI: $10.1002 /$ jso.24462

16 Yano S, Takehara K, Miwa S, Kishimoto H, Hiroshima Y, Murakami T, Urata Y, Kagawa S, Bouvet M, Fujiwara T and Hoffman RM: Improved resection and outcome of colon-cancer liver metastasis with fluorescence-guided surgery using in situ GFP labeling with a telomerase-dependent adenovirus in an orthotopic mouse model. PLoS One 11(2): e0148760, 2016. PMID: 26849435. DOI: 10.1371/journal.pone.0148760

17 Kawaguchi K, Murakami T, Suetsugu A, Kiyuna T, Igarashi K, Hiroshima Y, Zhao M, Zhang Y, Bouvet M, Clary BM, Unno M and Hoffman RM: High-efficacy targeting of colon-cancer liver metastasis with Salmonella typhimurium A1-R via intra-portalvein injection in orthotopic nude-mouse models. Oncotarget 8(12): 19065-19073, 2017. PMID: 27683127. DOI: 10.18632/ oncotarget.12227

18 Oshiro H, Tome Y, Kiyuna T, Yoon SN, Lwin TM, Han Q, Tan Y, Miyake K, Higuchi T, Sugisawa N, Katsuya Y, Park JH, Zang Z, Razmjooei S, Bouvet M, Clary B, Singh SR, Kanaya F, Nishida 
K and Hoffman RM: Oral recombinant methioninase overcomes colorectal-cancer liver metastasis resistance to the combination of 5-fluorouracil and oxaliplatinum in a patient-derived orthotopic xenograft mouse model. Anticancer Res 39(9): 4667-4671, 2019. PMID: 31519565. DOI: 10.21873/anticanres.13648

19 Hoffman RM: Patient-derived mouse models of cancer. Humana Press, Springer Nature, 2017.

20 Hoffman RM: Orthotopic metastatic mouse models for anticancer drug discovery and evaluation: a bridge to the clinic. Invest New Drugs 17(4): 343-359, 1999. PMID: 10759402. DOI: 10.1023/a:1006326203858

21 Sugisawa N, Miyake K, Higuchi T, Oshiro H, Zhang Z, Park JH, Kawaguchi K, Chawla SP, Bouvet M, Singh SR, Unno M and Hoffman RM: Induction of metastasis by low-dose gemcitabine in a pancreatic cancer orthotopic mouse model: an opposite effect of chemotherapy. Anticancer Res 39(10): 5339-5344, 2019. PMID: 31570427. DOI: 10.21873/anticanres.13726

22 Yamamoto J, Murata T, Tashiro Y, Higuchi T, Sugisawa N, Nishino H, Inubushi S, Sun YU, Lim H, Miyake K, Hongo A, Nomura T, Saitoh W, Moriya T, Tanino H, Hozumi C, Bouvet M, Singh SR, Endo I and Hoffman RM: A triple-negative matrix-producing breast carcinoma patient-derived orthotopic xenograft (PDOX) mouse model is sensitive to bevacizumab and vinorelbine, regressed by eribulin and resistant to olaparib. Anticancer Res 40(5): 2509-2514, 2020. PMID: 32366395. DOI: 10.21873 /anticanres.14221
23 Yang M, Reynoso J, Bouvet M and Hoffman RM: A transgenic red fluorescent protein-expressing nude mouse for color-coded imaging of the tumor microenvironment.J Cell Biochem 106(2):279-284, 2009. PMID: 19097136. DOI: 10.1002/jcb.21999

24 Suetsugu A, Osawa Y, Nagaki M, Moriwaki H, Saji S, Bouvet $M$ and Hoffman RM: Simultaneous color-coded imaging to distinguish cancer "stem-like" and non-stem cells in the same tumor. J Cell Biochem 111(4): 1035-1041, 2010. PMID: 20672309. DOI: $10.1002 /$ jcb.22792.

25 Hoffman RM: Patient-derived orthotopic xenografts: better mimic of metastasis than subcutaneous xenografts. Nat Rev Cancer 15(8): 451-452, 2015. PMID: 26422835. DOI: $10.1038 /$ nrc3972

26 Kuo TH, Kubota T, Watanabe M, Furukawa T, Teramoto T, Ishibiki K, Kitajima M, Moossa AR, Penman S and Hoffman RM: Liver colonization competence governs colon cancer metastasis. Proc Natl Acad Sci USA 92(26): 12085-12089, 1995. PMID: 8618849. DOI: 10.1073/pnas.92.26.12085

Received July 1, 2020

Revised July 24, 2020

Accepted July 27, 2020 